\title{
Race to the Bottom? Local Tax Break Competition and Business Location
} (Online Appendix)

\author{
Evan Mast* \\ June 5, 2019
}

This appendix contains further details about the exercises in main text. Section I contains more information about IDAs and other forms of business tax breaks in New York. Section II describes data sources and the data construction process in more detail. Section III provides further information on the model and its estimation/identification. Finally, Section IV provides additional figures and tables.

\section{Details on IDAs and Other New York Programs}

IDAs are generally operated by a board of 3-7 people, who are appointed by the local government of the jurisdiction the IDA represents. In some cases, the board members are volunteers, but they are often paid, especially at more active IDAs. IDAs generate revenue from application and operating fees, returns on their properties and investments, and state subsidies and grants.

The legal process for IDA incentives is somewhat convoluted. Properties owned by IDAs are exempt from all property and mortgage recording taxes, and their purchases are exempt from sales taxes. IDAs pass these exemptions onto projects they support in a variety of ways. In one common arrangement, a company transfers the title to a property to the IDA,

\footnotetext{
${ }^{*}$ Upjohn Institute, evanemast@gmail.com.
} 
the IDA leases the property to the company at no cost, and then the IDA transfers the title back to the company at the conclusion of the project. Since the IDA technically owns the property, no taxes are due while the IDA holds the title. However, for property tax exemptions, IDAs will usually require businesses to agree to a schedule of Payments in Lieu of Taxes (PILOTs) equal to some percentage of the property taxes that would normally be due on the property. PILOTs are then distributed between the local, school, and county governments. PILOT payments are typically not made for sales tax exemptions - the firm pays none of the tax. Another common arrangement is for IDAs to issue debt on behalf of companies, use the proceeds to buy a property, and then lease the property to the company at a nominal rate.

In addition to tax exemptions, IDAs may also confer state or federal income tax exemptions on bonds issued by a firm. Interest on these bonds is exempt from income taxes, enabling firms to offer lower interest rates and obtain cheaper financing. There is a statewide limit on how many bonds may receive federal exemptions from IDAs, but no such limit exists for state tax exempt bonds. Lynch et al. (1996) estimate that between 1987-1991 the amount of foregone state income tax from these bonds was approximately $25 \%$ of the total exemptions given directly to companies. Extrapolating to the present, this implies that $\$ 165$ million in personal income tax exemptions is foregone annually as a result of IDA tax exemptions on bond returns.

While IDAs are the major agents for local economic development in New York State, there were a variety of other tax incentive programs active during the sample period. The three largest by far are the Brownfield Cleanup Program, the Empire State Film Production Credit, and the Empire Zone program. The Brownfield program encourages the redevelopment of old industrial sites ("brownfields") and provided about $\$ 500$ million in state tax credits in 2013. The film production credit provided $\$ 380$ million in state tax credits and sales tax exemptions in 2013. While the Empire Zone program was closed to new entrants in 2010, in 2008 it provided tax credits totaling nearly $\$ 600$ million to firms located in blighted areas. Localities also had the highest degree of control over Empire Zone exemptions, as they were administered by local entities called a Zone Area Board, though some decisions also required state approval. 
A crucial difference between these programs and IDAs is that they primarily provide credits against state taxes, whereas IDAs mainly offer exemption on local taxes. Additionally, these programs restrict which firms may receive exemptions - Brownfield credits can only be given to firms rehabilitating old industrial sites, Empire Zone credits may only be given to firms in blighted areas, and the film credits only benefit one highly specialized industry. Local officials have less discretion in administering these tax credits, and evidence in Appendix Table A2 suggests that they do not compete on this margin,

\section{Data}

\section{II.A Variable Construction}

Most variables I take directly from the data sources described in Section IC of the main text, but some require modification before being used in the analysis. In order to generate demographic information for towns in New York, which are not a standard Census geographic level, I aggregate Census block group data, linearly interpolating when borders of block groups do not align with borders of towns. In order to generate town-level information on IDA agreements, I simply collapse the main IDA data by town.

I modify several firm-level variables to facilitate the estimation of the structural model. First, I set the year of the firm's arrival to two years after its approval date. This appears to be the modal delay in the data (relatively few projects receive exemptions sooner than two years after the date the agreement is signed) and helps identify the project's cohort of arriving firms in the ReferenceUSA data.

Second, I map the firm sectors provided by IDAs into sectors consistent with the NAICs codes in the ReferenceUSA data. I map Wholesale Trade and Retail Trade into the retail sector; Finance, Insurance, and Real Estate into the finance sector, Manufacturing into the manufacturing sector, and Services and Construction into the services sector. This mapping is inexact in some cases, and I use project descriptions provided by the IDAs to help determine the appropriate classification.

Third, I prepare project property values and number of employees for the estimation. The 
number of full-time equivalent number of employees at a location is reported directly in the data. I impute assessed property values using before-exemption property tax liability and tax rates. ${ }^{1}$ While most projects have both of these variables, a small percentage are missing employment. I use property value to impute employment in these cases. For example, for a manufacturing project that has a property value but is missing employee information, I regress number of employees on property value for manufacturing projects that contain both values and use the estimates to predict employees for the project that has only a property value recorded.

Since employment and assessed property value fluctuate, I have to make assumptions about the level of employment/property value that IDAs consider when forming their valuations of a firm. This may be especially difficult when projects are in their early years and may not be fully built or at full employment. For a project that was active in both 2008 and 2013, I take employment and property value to be the maximum observed. For projects that were at least five years old in 2008 and were not active in 2013, I take employment and property value to be what was observed in 2008. Finally, for projects that were active in only one of 2008 or 2013 and were less than five years old when observed, I take a more complicated approach. First, I compute the median growth rate in property value and employment from 2008 to 2013 for projects that were less than five years old in 2008 and still active in 2013. Then, for a given observation, I multiply the observed property value/employment by the median observed growth rate of that variable, prorated according to how old the project was at the time of observation. For example, for a project that was two years old in 2013, I multiply its observed property value by the median property value growth multiplied by 6 to arrive at its final property value.

Fourth, in some agreements, exemptions apply to the taxes on only a portion of the property value. ${ }^{2}$ For example, if a firm renovates a building, it might receive exemptions only on the increase in assessed value from the renovation, but not on the original value of the building. Only 12\% of agreements in 2008 and 17\% in 2013 had such arrangements in

\footnotetext{
${ }^{1}$ Since, for reasons described in Section IIB of the Appendix, county tax rates are the most reliable, I use county tax rates and liabilities to compute assessed values whenever possible. For about $10 \%$ of observations, either the county tax rate or liability is 0 , and I use the municipal values in these cases.

${ }^{2}$ This is similar to the tax increment financing structure frequently used in other areas of the country.
} 
which the exempt portion of the assessed value was less than $80 \%$ of the full assessed value. Because it's hard to predict what percent of project value would be exempted in different locations and the vast majority of projects receive exemptions on close to the full assessed value, I assume in the model that exemptions always apply to the full assessed value.

Finally, I compute an average property rate for each town. This computation is somewhat complicated, and I describe it separately in the next subsection.

\section{II.B Property Tax Rates}

To compute the average property tax rate in a town, I first pull the full-value rates ${ }^{3}$ for each taxing jurisdiction from New York's Overlapping Property Tax Table. Counties, schools, municipalities, and special districts may all levy property taxes on a given parcel. Because some school districts charge different rates in different municipalities, I average these rates to arrive at a single number per district. These tables include the average rate for special districts in a town in the town tax rate. Data is available to compute these rates for 2008-2013

Second, because the overlapping tax tables average together the residential and nonresidential rate, I manually collect the non-residential rate for the roughly 100 taxing jurisdictions that collect different taxes on different types of property. These tax rates are not stored in a centralized location and are generally only available for the current year on town websites. I was able to collect both the rates and the non-residential/residential ratio for about $80 \%$ of the jurisdictions, and I assume that the remaining $20 \%$ have a nonresidential/residential ratio equal to the average over the jurisdictions whose data I was able to collect.

The above two steps leave me with a non-residential tax rate for each taxing jurisdiction. Next, for a given town, I compute the average county, school, and village non-residential taxes according to the percent of the town's land area that is in a given county/district/village. Recall that I use towns and a small number of large villages ${ }^{4}$ as my sample of municipalities.

\footnotetext{
${ }^{3}$ Full-value rates are adjusted to represent mils per market value of property. Some towns also report rates as mils per assessed dollar of property, where their assessed value is a proportion of market value.

${ }^{4}$ Villages are subsets of towns in New York State. Most are very small, with only a few hundred residents.
} 
When I include a village as a separate observation, I consider the town the village is in to be not the full town, but the town less the land area taken by the village. I thus do not include these villages' tax rate in their containing town's average tax rate. For small villages which I do not include as separate observations, I simply average the village tax rate over the town according to land area.

Finally, I sum a town/large village's average non-residential tax rates for all jurisdictions collecting tax and arrive at an average property tax rate for a given year. I compute these averages for 2008 and 2013 and take them as the town tax rate in that year.

These property tax rates serve two main purposes in this paper. First, they help impute assessed values, as described in Section IIA of this Appendix. For imputing assessed values, I need separate rates by taxing jurisdiction in 2008 and 2013. Because the county tax rate is easier to pin down than school district rates or village rates that may be different in different parts of the town, I use county taxes in the imputation whenever possible.

Second, property taxes enter the firm's objective function in the model, where I need a firm's expectation of the average property tax rate in a given location, which is more complicated. Since property taxes are stable over time, ${ }^{5}$ I take the average of the rates in 2008 and 2013 to arrive at the rate a firm considers.

\section{II.C Model}

\section{II.D Model with County IDAs}

The model presented in the main text is slightly simplified, as I discuss only towns, rather than town and county IDAs. While I treat town IDAs identically to how I describe towns in the text, county IDAs have a more complicated problem, as they may offer subsidies and care about welfare in a number of towns. I assume that for each arriving firm, they offer a uniform exemption for locating in any town in the county that does not have its own IDA. Each town in the county draws a value for firm $f$, and the county IDA chooses a uniform exemption to maximize the expected value among its towns. County $c$ then faces a very similar objective function to town IDAs:

\footnotetext{
${ }^{5}$ At least over the 2007-2014 period for which I have data.
} 


$$
E\left(V_{f c} \mid b_{f c}, b_{f(-c)}\right)=\sum_{i \in c}\left(P\left(\text { win }_{f i} \mid b_{f c}, b_{f(-c)}\right) * v_{f i}\right)
$$

where $b_{f c}$ is the exemption offered in each town.

\section{II.E Sample Restrictions}

I apply a number of restrictions to construct the sample of projects used in model estimation. First, in order to remain consistent with the model of profit-maximizing mobile firms, I continue to exclude civic projects, projects managed by nonprofits, agricultural/forestry/fishing projects, and transportation/communication/electric projects from the sample. Second, because the model predicts that IDAs will compete on local taxes and meet firm's requests on state taxes, I include only projects that receive exemptions on local taxes. ${ }^{6}$ Lastly, in order to avoid reporting inaccuracies and legacy projects, I exclude the small number of active projects that began receiving exemptions before 1993. Because these restrictions shrink the size of the sample, I utilize the 2008 data in addition to the 2013 data. This enables me to include firms that received exemptions in 2008 but not in 2013, expanding my sample to 2,224 firm-specific agreements.

Because IDA projects last multiple years, I have to be careful to not count projects that are in both the 2008 and 2013 data as separate observations. I am able to match about half of the 2008 projects to the 2013 data, enabling me to simulate their arrival once and come up with exemptions for both 2008 and 2013. About a third of 2008 projects expire before 2013. I can simulate these firms and assume that they do not receive exemptions in 2013. The remaining $15 \%$ of 2008 projects do not expire and do not match any projects in the 2013 data. This may occur because the firms go out of business, ${ }^{7}$ because the agreements are retracted or renegotiated under a different name, or because of data errors or changes in project descriptions. I drop these agreements. There are also a small amount of agreements (8\%) in the 2013 data that list a start year prior to 2008 but do not appear in the 2008 data. I also drop these agreements, which likely represent errors in record keeping, leaving 2,224

\footnotetext{
${ }^{6}$ Some firms receive only sales tax exemptions on purchases.

${ }^{7}$ Bear Stearns disappears from the data, for example.
} 
observations in the final sample.

\section{II.F Model Implementation}

Section IVB of the main text provided an overview of the algorithm I use to estimate the structural parameters of the model. I implement this procedure using the Optimization Toolbox in Matlab. The major challenge of the estimation is ensuring that a solution is a global optimum rather than a local optimum. For each specification that I estimate, I first run a large, coarse grid over the parameter space to provide some idea of the shape of the objective function. I then run a hybrid simulated annealing/pattern search algorithm from three randomly chosen starting points. This hybrid algorithm simply runs a simulated annealing search followed by a pattern search, taking the solution to the annealing search as the starting point for the pattern search. I confirm that searches using these diverse starting points converge to very similar parameters. I take the solution with the lowest distance metric as the parameter estimate for a given specification. Finally, I compare the distance metric associated with the parameter estimate to distance metrics on the coarse grid and confirm that no other parts of the grid yield a smaller distance metric. I compute standard errors according to the standard sandwich formula with numerically simulated derivatives.

\section{II.G Identification of Model Parameters}

Section IVC of the text provided an overview of the identification of model parameters. In this section, I perform some simulations to provide more detail. Beginning with firm profit, the parameter $\beta_{\text {dist }}$ is primarily identified by the set of regression coefficients $\bar{\gamma}=$ $\left\{\gamma_{25}, \gamma_{30}, \gamma_{35}, \gamma_{40}\right\}$. Appendix Figure A5 shows simulations of $\bar{\gamma}$ under three values of $\beta_{\text {dist }}$.

When $\beta_{\text {dist }}=-2.5$, as shown in the dashed line, competition is generally low and fades out quickly. When $\beta_{\text {dist }}=-1.66$, in contrast, competition has a much larger effect on exemptions, because IDAs gain more from offering the marginal exemption. When $\beta_{\text {dist }}$ moves to -1.33 , two changes occur. First, competition fades out more slowly with distance, as $\gamma_{35}$ and $\gamma_{40}$ increase. This occurs because when $\beta_{\text {dist }}$ is smaller, IDAs from a greater distance can 'make up' for their poor location with tax breaks and influence the bids in an auction. Additionally, 
$\gamma_{25}$ decreases slightly, because it takes less competition to induce towns to make the maximum bid and additional IDAs beyond that point generate no further changes. This flattens the relationship between IDAs and exemptions and shrinks the regression coefficient. These distinct shapes of $\bar{\gamma}$ identify $\beta_{\text {dist }}$.

Turning to town's valuation of firms, $\kappa_{\text {prop }}$ and $\kappa_{e m p}$ are primarily identified by the sum and 25th percentile of exemptions. Appendix Figure A6 shows how the sum monotonically increases with increases in $\kappa_{\text {prop }},{ }^{8}$ as towns are willing to offer a larger tax break when they value a firm more. Of course, a given sum and 25th percentile could be produced by a large $\kappa_{e m p}$ and small $\kappa_{\text {prop }}$ or vice versa. The correlation between a project's number of jobs and received exemption identifies the relative importance of jobs and property value.

In addition to the relationships shown in Appendix Figures A5 and A6, increases in the town valuation parameters generally shift $\bar{\gamma}$ up and increases in $\beta_{\text {dist }}$ decrease the sum of tax exemptions. However, crucially for unique identification of the structural parameters, one cannot simply increase both of these parameters and have no effect on the simulated moments.

For example, suppose that, starting from a locally optimal set of parameters, one increases $\kappa_{\text {prop }}$ and increases $\beta_{\text {dist }}$. This may replicate the sum and 25 th percentile of subsidies if the changes are made so that the change in $\kappa_{\text {prop }}$ exactly offsets the change in $\beta_{\text {dist }}$, but it will change $\bar{\gamma}$. Increasing $\beta_{\text {dist }}$ steepens the gradient of $\bar{\gamma}$, making competition fade out more quickly with distance, while increasing the town valuation parameters only shifts $\bar{\gamma}$ down without affecting the gradient. Thus, this change will have a negative effect on this dimension of model fit.

\footnotetext{
${ }^{8}$ The pattern is very similar for $\kappa_{e m p}$.
} 


\section{II.H Appendix Figures and Tables}

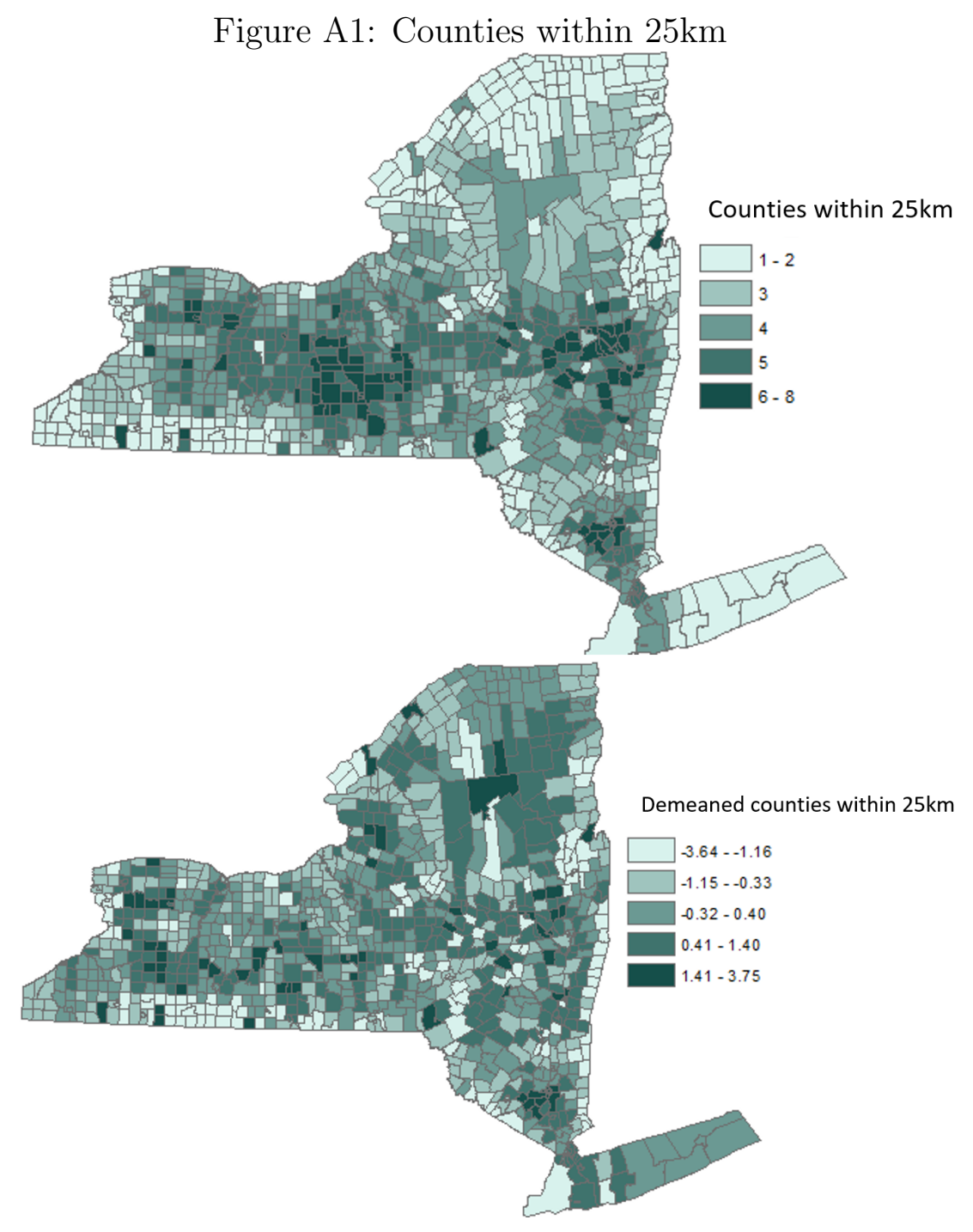

Note: The number of counties within 25 kilometers of towns in New York State. The boxes represent towns, colored according to the number of counties within 25 kilometers. The top panel uses the raw number of counties, showing the variation that would drive estimates without county fixed effects. The bottom panel demeans at the county level, showing the variation driving the estimates with county fixed effects. 
Figure A2: Covariate and Instrument Predictions of IDAs within $25 \mathrm{~km}$

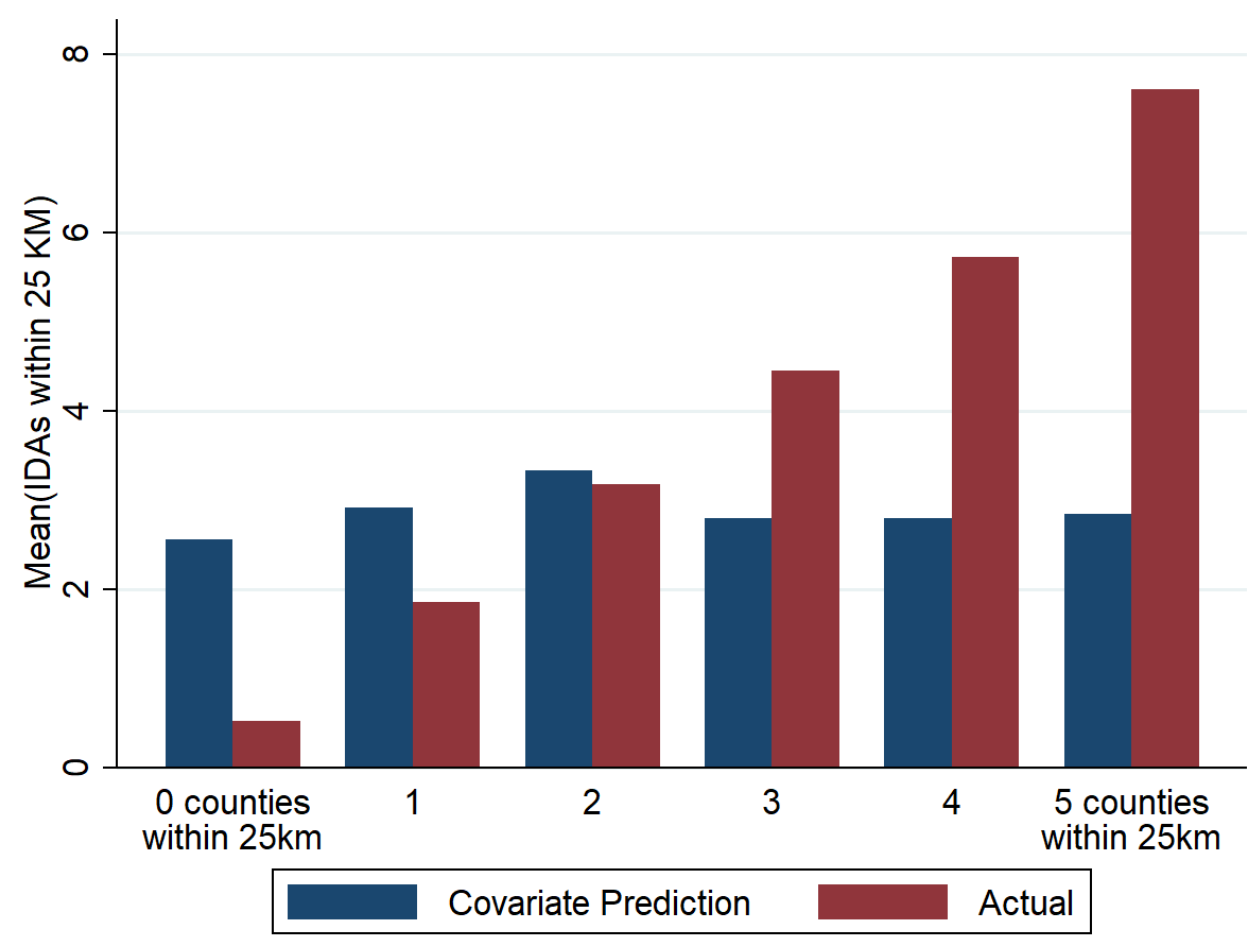

Note: This figure shows the relative power of the instrument versus other covariates in predicting the number of IDAs within 25 kilometers. The red bars show the mean number of IDAs within 25 kilometers of towns with a given number of nearby counties. The blue bars show the mean predicted number of IDAs within 25 kilometers of towns with a given number of nearby counties, where the prediction is based on the covariates included in the balancing tests in the main text. 
Figure A3: Effect of Competition on Average Exemptions in 2008, 2013, and 2016 Panel A: Dependent variable $=\log ($ total exemptions +1$)$

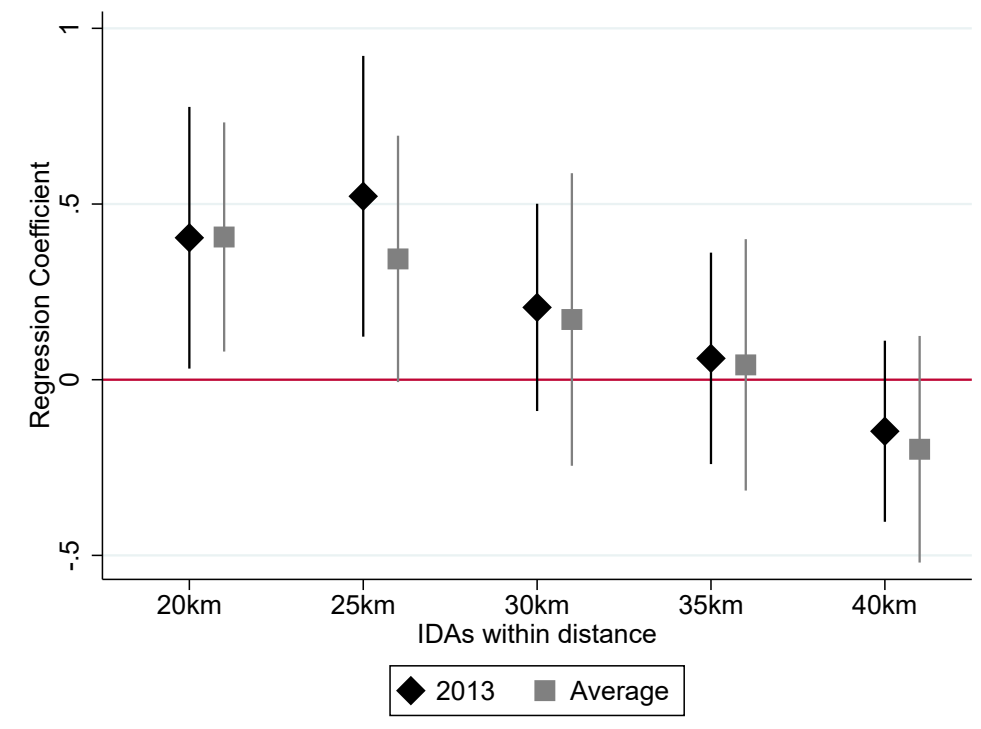

Panel B: Dependent variable $=1$ (any exemptions)

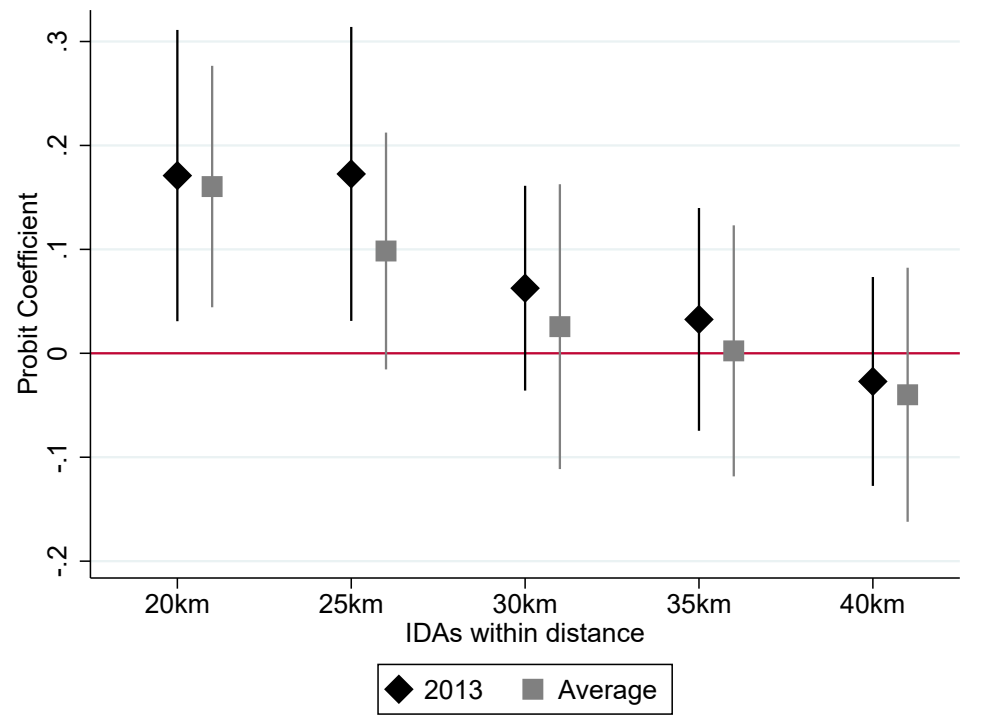

Note: This figure compares the estimated effect of competition on exemptions in 2013 to the estimated effect on average exemptions across the years 2008, 2013, and 2016. The black diamonds represent the coefficients on IDAs within $X$ kilometers from Table 4. The gray squares show the same coefficients from repeating those regressions with average exemptions across 2008, 2013, and 2016 as the dependent variable. In the top panel, the dependent variable is the log of one plus the sum of exemptions across the three years. In the bottom panel, the dependent variable is an indicator for whether a particular town had exemptions in any of the years 2008, 2013, or 2016. Bars represent $95 \%$ confidence intervals with errors clustered at the county level. For more detail on the specification, see the note to Table 4 . 
Figure A4: Model fit of matched and unmatched moments

Panel A: Matched moments

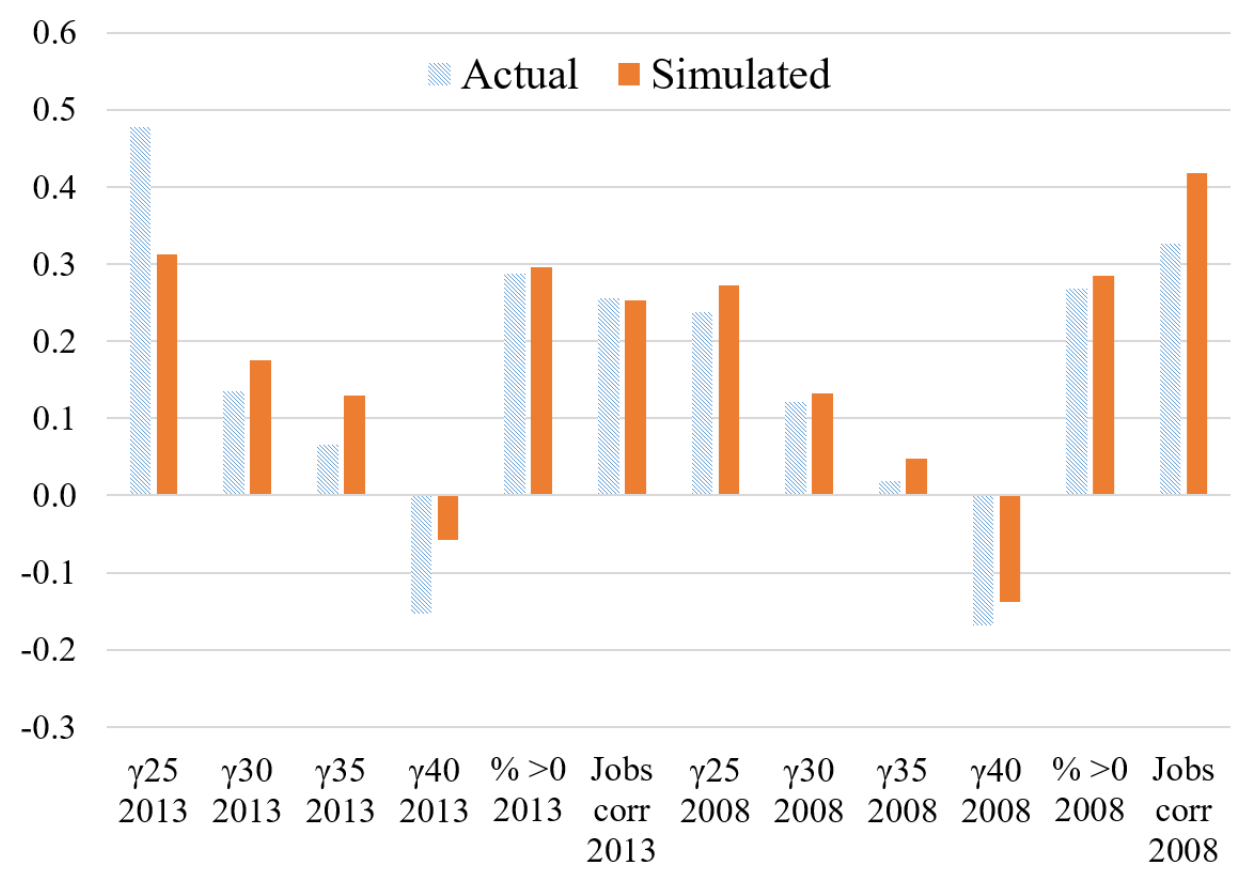

Panel B: Unmatched moments

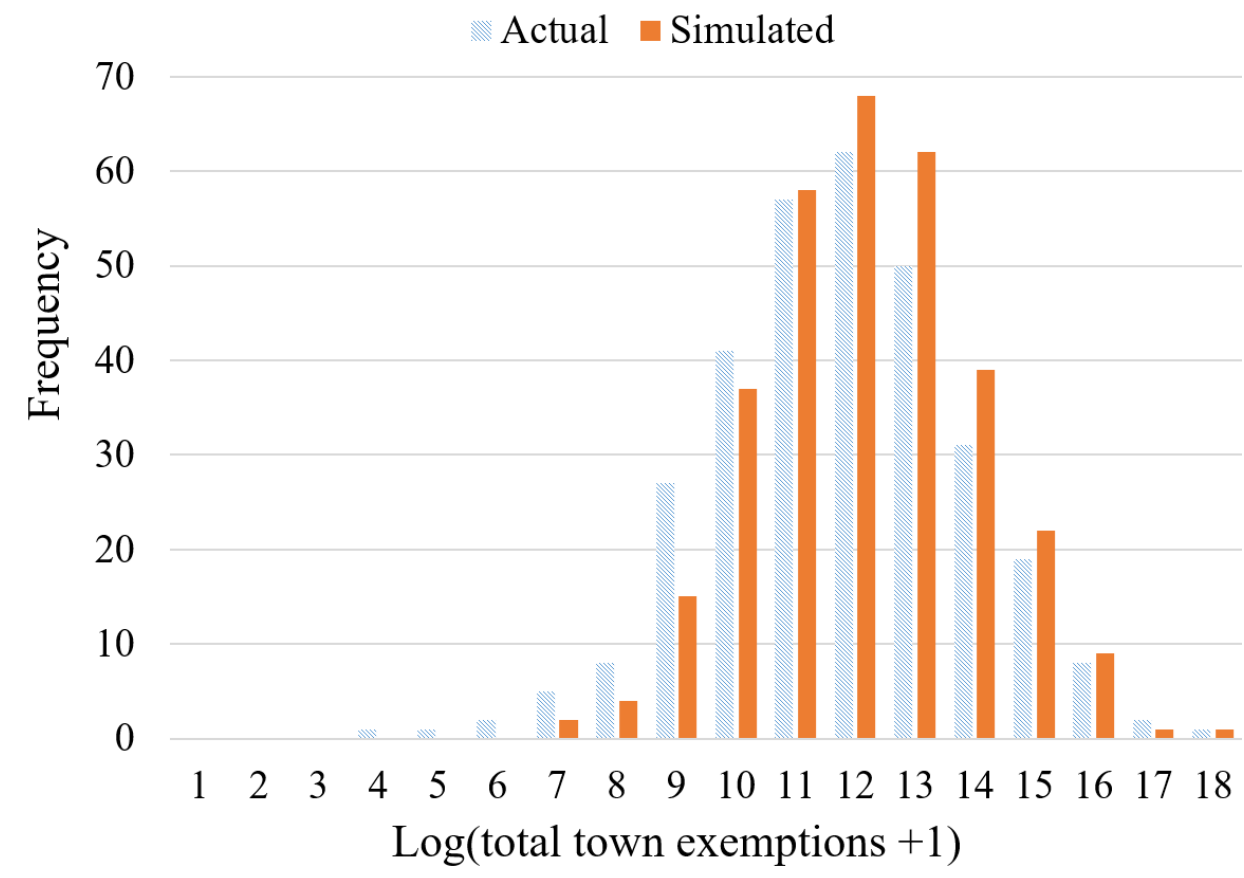

Note: Actual and simulated moments. In the top panel, the light bars show the actual data moments, and the dark bars, the simulated moments under the full sample estimates in Table 5 with $\sigma=1.66$. All moments in this panel were used in the estimation. The bottom panel shows the simulated and actual distribution of total town exemptions, which was not matched in estimation. 
Figure A5: Identification of $\beta_{\text {dist }}$

\section{4}

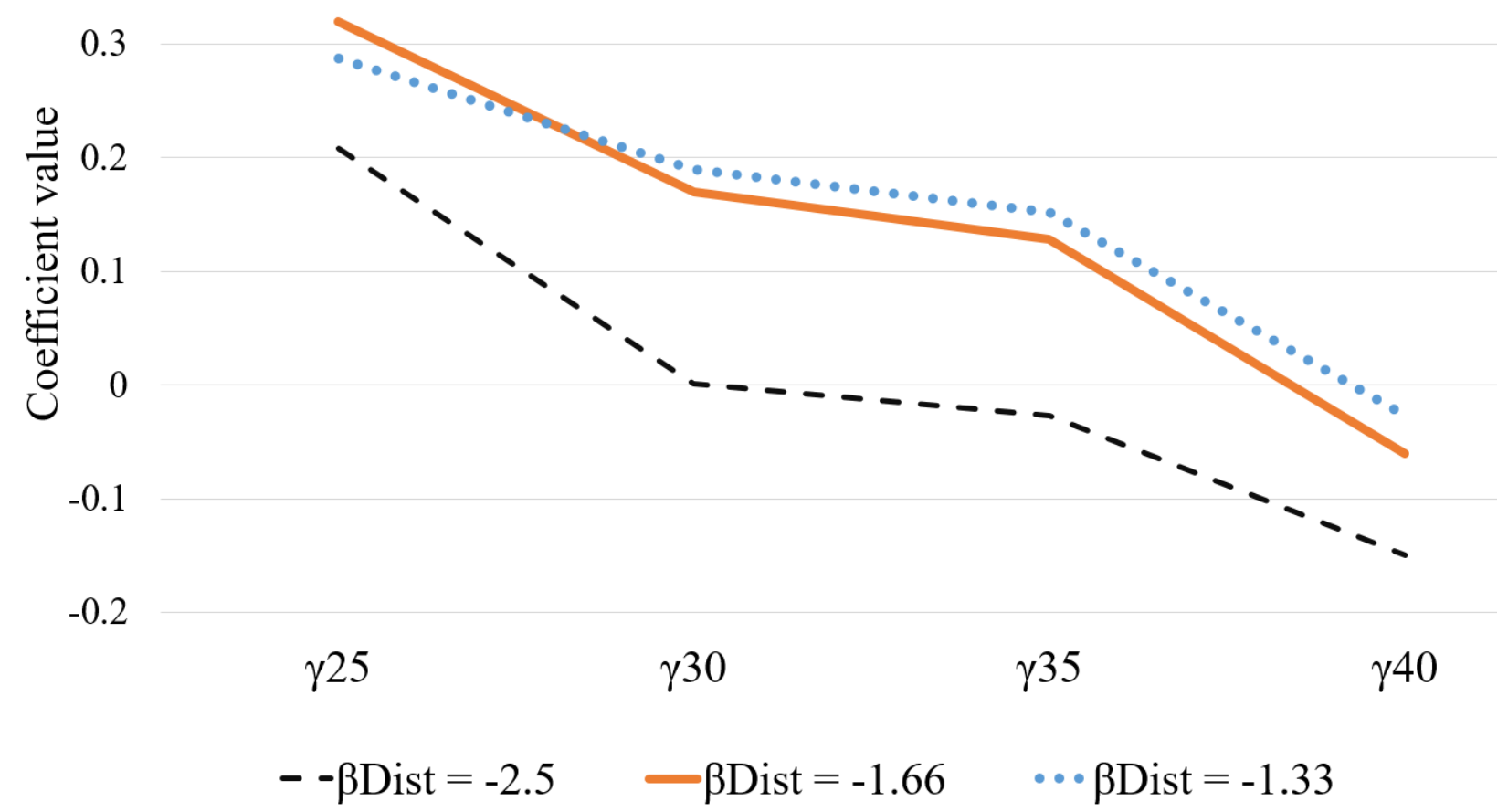

Note: Each line in the graph represents the simulated values of $\left\{\gamma_{25}, \gamma_{30}, \gamma_{35}, \gamma_{40}\right\}$ under a given value of $\beta_{\text {dist }}$, holding the other structural parameters constant at the estimated values. $\beta_{\text {dist }}$ is the disutility of distance in the firm decision, with larger values implying that tax breaks are less important in firm decisions. $\gamma_{x}$ is the coefficient on IDAs within $\mathrm{x}$ kilometers from an estimate of the IV specification in Column 4 of Panel B of Table 3 with a radius of $\mathrm{x} \mathrm{km}$ (rather than 25) on the nearby IDAs measure. Larger observed $\left\{\gamma_{25}, \gamma_{30}, \gamma_{35}, \gamma_{40}\right\}$ that fade out more slowly with distance imply that tax breaks are more important relative to distance, leading to smaller estimates of $\beta_{\text {dist }}$. 
Figure A6: Identification of $\kappa_{\text {prop }}$
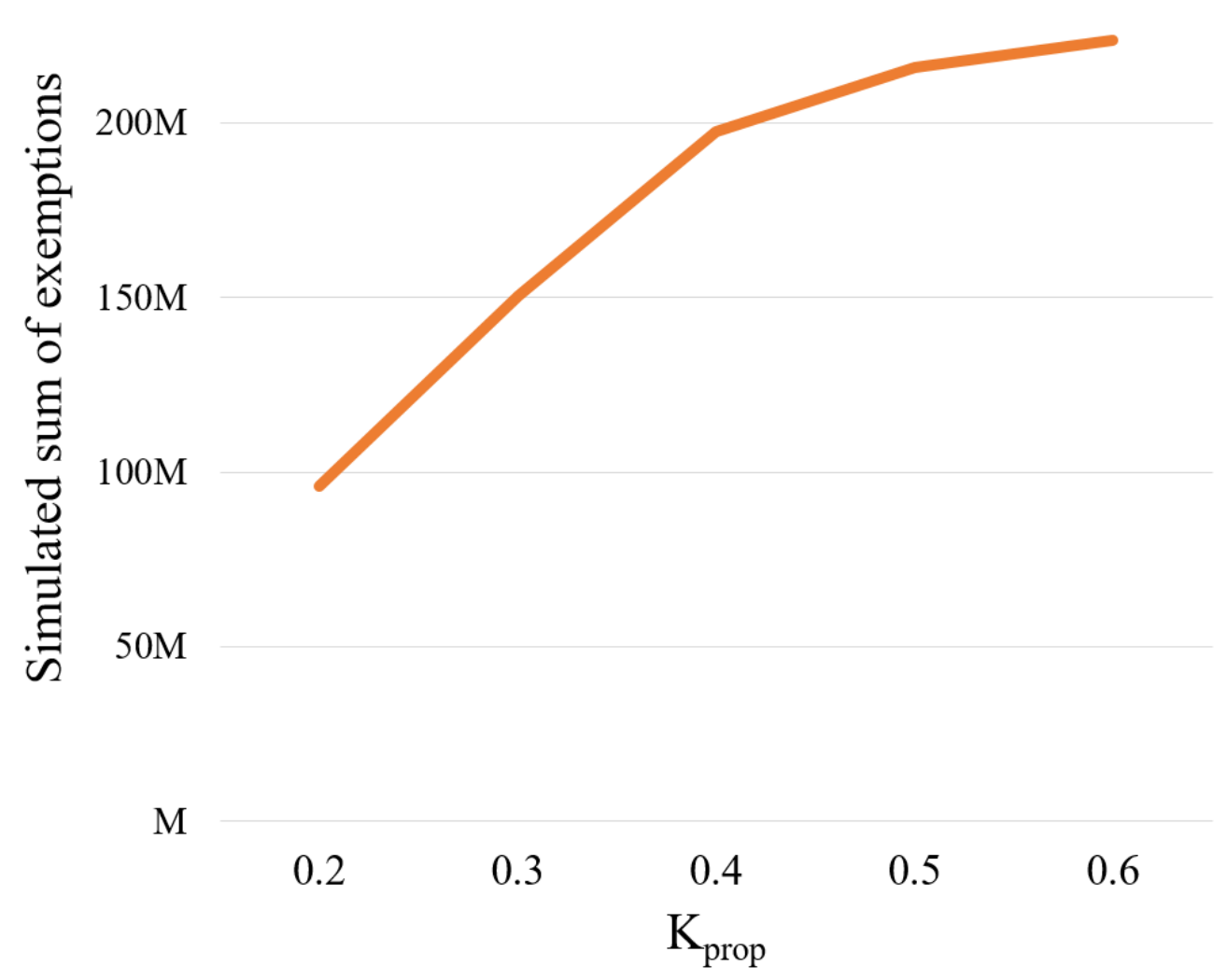

Note: The line represents the simulated values of the sum of IDA exemptions for a given value of $\kappa_{\text {prop }}$ (town's valuation of a business's property value), holding the other structural parameters constant at the estimated values. The higher the sum of exemptions, the larger the estimated $\kappa_{\text {prop }}$. A similar graph can be generated for $\kappa_{e m p}$, which is town's valuation of a business's jobs. The two parameters are separately identified by matching the correlation between a project's exemptions and its number of full-time equivalent employees. 
Table A1: Characteristics of towns with IDAs

\begin{tabular}{lccc}
\hline \hline & $\begin{array}{c}(1) \\
\text { Towns with own IDA }\end{array}$ & $\begin{array}{c}(2) \\
\text { Other towns }\end{array}$ & $\begin{array}{c}(3) \\
\text { Difference }\end{array}$ \\
\hline Population & 61,964 & 7,706 & 54,258 \\
& & & $(13.3)$ \\
Manu. employment percent & 5.02 & 6.28 & -1.25 \\
& & & $(3.19)$ \\
Percent white & 77.7 & 93.3 & -15.5 \\
& & & $(11.7)$ \\
Percent below poverty line & 10.3 & 7.6 & 2.79 \\
& & & $(3.6)$ \\
IDAs w/i 25km & 5.58 & 2.78 & 2.79 \\
& & & $(8.3)$ \\
$2006-2010$ average unemployment rate & 7.13 & 6.86 & 0.26 \\
& & & $(0.6)$ \\
\hline $\mathrm{N}$ & 50 & 1045 & \\
\hline \hline
\end{tabular}

Note: Characteristics of towns with/without their own IDAs. T-statistics appear in parentheses in the differences column. All demographic variables are taken from the 2006-2010 ACS. I drop New York City to avoid skewing means. 
Table A2: Heterogeneity by taxing body

\begin{tabular}{lccccc}
\hline \hline & $(1)$ & $(2)$ & $(3)$ & $(4)$ & $(5)$ \\
Dependent variable: & $\log ($ county taxes+1) & $\log ($ school taxes+1) & $\log ($ town taxes+1) & $\log ($ state taxes+1) & $1($ Empire Zone $)$ \\
\hline IDAs within $25 \mathrm{~km}$ & .409 & .461 & .506 & .236 & -0.008 \\
(S.E.) & $(.158)$ & $(.181)$ & $(.152)$ & $(.127)$ & $(.067)$ \\
\hline Town observations & 1092 & 1091 & 1085 & 1096 & $\mathrm{Y}$ \\
Town controls & $\mathrm{Y}$ & $\mathrm{Y}$ & $\mathrm{Y}$ & $\mathrm{Y}$ & $\mathrm{Y}$ \\
County fixed effects & $\mathrm{Y}$ & $\mathrm{Y}$ & $\mathrm{Y}$ & 1096 \\
\hline \hline
\end{tabular}

Note: Results from regressions of tax exemptions to different levels of government on the number of nearby IDAs. All regressions use counties within $25 \mathrm{~km}$ as an instrument for IDAs within $25 \mathrm{~km}$. County, school, and municipal taxes are property taxes. State taxes are sales taxes. Empire Zones confer state tax credits on firms within their boundaries. Town controls are listed in Section III of the main text. Standard errors are clustered at the county level. In the left four columns, some observations are dropped because a small number of towns had negative tax exemptions in a particular category, generally because of an exemption agreement specified in dollars, rather than percentages. 
Table A3: Selectively dropping areas of the state

\begin{tabular}{|c|c|c|c|c|c|c|c|c|}
\hline \multirow[b]{2}{*}{ Dependent Variable: } & (1) & $(2)$ & $(3)$ & $(4)$ & (5) & (6) & (7) & (8) \\
\hline & \multicolumn{4}{|c|}{ 1(exemptions in 2013) } & \multicolumn{4}{|c|}{$\log ($ exemptions in $2013+1)$} \\
\hline \multirow[t]{2}{*}{ IDAs within $25 \mathrm{~km}$} & .144 & .131 & .091 & 0.068 & .401 & .523 & .438 & .336 \\
\hline & $(.056)$ & $(.063)$ & $(.044)$ & $(.051)$ & $(.178)$ & $(.222)$ & $(.164)$ & $(.182)$ \\
\hline Marginal effect at median & 0.046 & 0.044 & 0.031 & 0.026 & & & & \\
\hline Dropped area & NYC Metro & Albany & Buffalo & Upstate & NYC Metro & Albany & Buffalo & Upstate \\
\hline $\mathrm{N}$ & 897 & 1037 & 1047 & 905 & 897 & 1037 & 1047 & 905 \\
\hline Town controls & $\mathrm{Y}$ & $\mathrm{Y}$ & $\mathrm{Y}$ & $\mathrm{Y}$ & $\mathrm{Y}$ & $\mathrm{Y}$ & $\mathrm{Y}$ & $\mathrm{Y}$ \\
\hline County fixed effects & $\mathrm{Y}$ & $\mathrm{Y}$ & $\mathrm{Y}$ & $\mathrm{Y}$ & $\mathrm{Y}$ & $\mathrm{Y}$ & $\mathrm{Y}$ & $\mathrm{Y}$ \\
\hline
\end{tabular}

Note: This table repeats the IV specifications in Column 4 of Panels A and B in Table 3. Each column represents a separate regression in which certain areas of the state are selectively dropped. 
Table A4: Alternative specifications

\begin{tabular}{lcccc}
\hline \hline & $(1)$ & $(2)$ & $(3)$ & $(4)$ \\
Specification: & IV & IV Tobit & IV & IV \\
Dependent Variable: & 1(any exemptions) & log(exemptions +1$)$ & $\begin{array}{c}\text { Inverse hyperbolic } \\
\text { sine (exemptions) }\end{array}$ & $\begin{array}{c}\text { \% establishments } \\
\text { receiving exemptions }\end{array}$ \\
\hline IDAs within X km & .045 & 1.43 & .572 & .0012 \\
& $(.018)$ & $(.543)$ & $(.223)$ & $(.0005)$ \\
\hline Mean DV & 0.363 & 4.26 & 3.96 & 0.0041 \\
$\mathrm{~N}$ & 1096 & 1057 & 1096 & 1096 \\
Controls & $\mathrm{Y}$ & $\mathrm{Y}$ & $\mathrm{Y}$ & $\mathrm{Y}$ \\
County fixed effects & $\mathrm{Y}$ & $\mathrm{Y}$ & $\mathrm{Y}$ & $\mathrm{Y}$ \\
\hline \hline
\end{tabular}

Note: This table shows several alternative specifications for the regressions reported in Table 3. Column 1 shows results from a linear probability model. Column 2 shows a tobit specification. Column 3 uses the inverse hyperbolic sine of exemptions rather than $\log ($ exemptions +1$)$. Column 4 uses the percent of establishments receiving exemptions as the dependent variable and, in order to avoid division bias, omits establishment count control variables. In Column 2 , some observations are dropped because some counties have either no exemptions or exemptions in every town. I use counties within 25 kilometers to instrument for IDAs within 25 kilometers. 
Table A5: Competition from close distances

\begin{tabular}{lcccccccc}
\hline \hline & $(1)$ & $(2)$ & $(3)$ & $(4)$ & $(5)$ & $(6)$ & $(7)$ & $(8)$ \\
Dependent Variable: & \multicolumn{2}{c}{$\log ($ exemptions } & in 2013+1) & \multicolumn{2}{c}{ log(exemptions in 2013+1) } \\
Number of IDAs in competition group & .248 & .334 & 0.228 & 0.161 & .434 & .409 & 0.233 & 0.058 \\
& $(.104)$ & $(.153)$ & $(.175)$ & $(.195)$ & $(.129)$ & $(.164)$ & $(.169)$ & $(.196)$ \\
\hline Competition group & $25 \mathrm{~km}$ & $20 \mathrm{~km}$ & $15 \mathrm{~km}$ & Border & $25 \mathrm{~km}$ & $20 \mathrm{~km}$ & $15 \mathrm{~km}$ & Border \\
$\mathrm{N}$ & 1096 & 1096 & 1096 & 1096 & 1096 & 1096 & 1096 & 1096 \\
Town controls & $\mathrm{Y}$ & $\mathrm{Y}$ & $\mathrm{Y}$ & $\mathrm{Y}$ & $\mathrm{Y}$ & $\mathrm{Y}$ & $\mathrm{Y}$ & $\mathrm{Y}$ \\
County fixed effects & $\mathrm{N}$ & $\mathrm{N}$ & $\mathrm{N}$ & $\mathrm{N}$ & $\mathrm{Y}$ & $\mathrm{Y}$ & $\mathrm{Y}$ & $\mathrm{Y}$ \\
\hline \hline
\end{tabular}

Note: This table repeats the OLS specification in Column 5 of Panel B of Table 3. Each column represents a separate regression in which the definition of competitors changes. The Border competition group uses the number of bordering IDAs as the measure of competition. Columns 1-4 do not include county fixed effects, while Columns 5-8 do. 
Table A6: Splitting firms by sector and size

\begin{tabular}{|c|c|c|c|c|c|}
\hline $\begin{array}{l}\text { Firm type: } \\
\text { Dependent Variable: }\end{array}$ & $\begin{array}{c}(1) \\
\text { Tradeable } \\
\text { 1(any exemptions) }\end{array}$ & $\begin{array}{c}(2) \\
\text { Non-tradeable } \\
1 \text { (any exemptions) }\end{array}$ & $\begin{array}{c}(3) \\
\text { Small }(\mathrm{FTE}<10) \\
1 \text { (any exemptions) }\end{array}$ & $\begin{array}{c}(4) \\
\text { Large }(\mathrm{FTE}>40) \\
1 \text { (any exemptions) }\end{array}$ & $\begin{array}{c}(5) \\
\text { Very large }(\mathrm{FTE}>125) \\
1 \text { (any exemptions) }\end{array}$ \\
\hline Mean DV & 0.225 & 0.278 & 0.198 & 0.234 & 0.158 \\
\hline $\mathrm{N}$ & 995 & 1057 & 983 & 983 & 818 \\
\hline County fixed effects & $\mathrm{Y}$ & $\mathrm{Y}$ & $\mathrm{Y}$ & $\mathrm{Y}$ & Y \\
\hline
\end{tabular}

Note: This table shows the effect of competition on exemptions to different subsamples of firms. Each column repeats the IV probit specification from Column 4 of Panel A of Table 3, but with an indicator for whether a town gave a tax break to any firms in a particular category as the dependent variable. Tradeable sectors are manufacturing and finance/corporate office, while non-tradeable are retail and services. Observation numbers change across columns because some counties have no towns granting exemptions to firms in a particular category and are then dropped from estimation. I use counties within 25 kilometers to instrument for IDAs within 25 kilometers. 
Table A7: Nonlinear effects of competition

\begin{tabular}{|c|c|c|c|c|}
\hline \multicolumn{5}{|c|}{ Panel A: Adding a squared term } \\
\hline & $(1)$ & $(2)$ & $(3)$ & $(4)$ \\
\hline Dependent variable: & 1(any exemptions) & 1(any exemptions) & $\log ($ exemptions +1$)$ & $\log ($ exemptions +1$)$ \\
\hline Specification: & OLS & IV & OLS & IV \\
\hline IDAs within $25 \mathrm{~km}$ & .056 & .067 & .65 & .754 \\
\hline (S.E.) & $(.024)$ & $(.028)$ & $(.296)$ & $(.324)$ \\
\hline IDAs within $25 \mathrm{~km}$ squared & -0.002 & -0.003 & -0.019 & -.034 \\
\hline (S.E.) & $(.001)$ & $(.002)$ & $(.02)$ & $(.027)$ \\
\hline Town observations & 1096 & 1096 & 1096 & 1096 \\
\hline Town controls & $\mathrm{Y}$ & $\mathrm{Y}$ & $\mathrm{Y}$ & $\mathrm{Y}$ \\
\hline County fixed effects & $\mathrm{Y}$ & $\mathrm{Y}$ & $\mathrm{Y}$ & $\mathrm{Y}$ \\
\hline \multicolumn{5}{|l|}{ Panel B: Including a spline } \\
\hline Dependent variable: & 1(any exemptions) & $\log ($ exemptions +1$)$ & & \\
\hline Specification: & OLS & OLS & & \\
\hline IDAs within $25 \mathrm{~km}(1-3)$ & 0.035 & 0.411 & & \\
\hline (S.E.) & $(.024)$ & $(.275)$ & & \\
\hline IDAs within 25 km (4-6) & .064 & .741 & & \\
\hline (S.E.) & $(.022)$ & $(.277)$ & & \\
\hline IDAs within 25 km (6-9) & 0.028 & 0.426 & & \\
\hline (S.E.) & $(.053)$ & $(.703)$ & & \\
\hline IDAs within 25 km $(9+)$ & 0.003 & 0.027 & & \\
\hline (S.E.) & $(.032)$ & $(.494)$ & & \\
\hline Town observations & 1096 & 1096 & & \\
\hline Town controls & $\mathrm{Y}$ & $\mathrm{Y}$ & & \\
\hline County fixed effects & $\mathrm{Y}$ & $\mathrm{Y}$ & & \\
\hline
\end{tabular}

Note: Estimates of the nonlinear effect of competition on tax breaks. IV regressions use number of counties within $25 \mathrm{~km}$ and the square of the predicted value of IDAs within $25 \mathrm{~km}$ (from the first stage of the regression reported in Column 4 of Panel B of Table 3) as instruments. IDAs within $25 \mathrm{~km}$ and IDAs within $25 \mathrm{~km}$ are instrumented for. Standard errors appear in parentheses. Town controls are listed in Section III of the main text. Standard errors are clustered at the county level. 
Table A8: Changes in simulated firm location across policy regimes

\begin{tabular}{|c|c|c|c|c|}
\hline $\begin{array}{c}\sigma \text { (s.d. in firm } \\
\text { profit) }\end{array}$ & $\begin{array}{l}\text { \% firms where s } \\
(1) \\
\text { Base parameters, } \\
\text { full sample }\end{array}$ & $\begin{array}{l}\text { of towns with }>\mathbf{2 5 \%} \\
\qquad(2) \\
\text { Sector specific } \\
\text { parameters, full sample }\end{array}$ & $\begin{array}{l}\text { lance of winning is sar } \\
\qquad(3) \\
\text { Sector specific } \\
\text { parameters, MF sample }\end{array}$ & $\begin{array}{c}\text { across counterfactuals } \\
(4) \\
\text { Sector specific } \\
\text { parameters, } R S \text { sample }\end{array}$ \\
\hline 1.25 & 74.7 & 82.8 & 83.2 & 82.4 \\
\hline 1.67 & 80.9 & 81.4 & 82.4 & 80.1 \\
\hline 2.5 & 81.1 & 82.5 & 82.5 & 82.4 \\
\hline
\end{tabular}

Note: Statistics on the number of firms where the set of towns with at least $25 \%$ chance of winning is the same across all counterfactual simulations under the parameter estimates reported in Table 5 . Rows show the calibrated value of $\sigma$, while the columns indicate the sample and parameter estimates used in simulations. The base parameters, full sample column shows results from simulations with all firms and full sample parameter estimates. Sector specific parameters, full sample shows results from simulations with all firms, but now applying the appropriate sector-specific parameters to each firm. The sector specific, MF sample column uses only manufacturing/finance firms and the parameters estimated from that sample, while the sector specific RS column does the same for retail/services firms. 